\title{
Current Evaluation of the Clinical Utility of Fluoromethylcholine-(18F) PET/CT in Prostate Cancer
}

\author{
Jean-Nöel Talbot ${ }^{1} *$ and Yanna-Marina Chevalme ${ }^{2}$ \\ ${ }^{1}$ Hôpital Tenon AP-HP et Université Pierre et Marie Curie; Paris - France, jean-noel.talbot@tnn.ap-hop-paris.fr; \\ ${ }^{2}$ AFSSAPS, St Denis - France
}

\begin{abstract}
This short review is dedicated to the current status of the assessment of a new PET radiopharmaceutical, fluoromethylcholine-(18F) or FCH, which is taken-up by prostate cancer tissue, in contrary to fluorodeoxyglucose$(18 F)$ or FDG. It seems that FCH could become "the FDG of prostate cancer", with the same type of achievements (detection of distant metastases and of occult recurrences, restaging prior to invasive treatments), and the same drawbacks (false negative results in case of small lesions, in particular lymph nodes metastases, and false positive results in case of infection/inflammation, in particular prostatitis). Current evidence is summarised and discussed for each of the potential settings of FCH PET/CT imaging in prostate cancer. The perspectives for granting a marketing authorisation to a FCH preparation are briefly analysed.
\end{abstract}

Key words: Fluoromethylcholine-(18F), PET/CT, prostate cancer, evaluation of radiopharmaceuticals

\section{INTRODUCTION}

Fluorodeoxyglucose-(18F) or FDG is not an accurate PET radiopharmaceutical in case of prostate cancer of a low aggressiveness. In this setting sensitivity and specificity of FDG PET/CT are both low. This is the reason why another PET radiopharmaceutical taken-up by prostate cancer of a low non-aggressiveness is actively searched for. Radiolabelled choline and choline analogues are among the most promising, since it has been demonstrated by MR spectroscopy (and used for diagnostic MR imaging) that the prostate cancer tissue contains high amounts of choline.

The main limitation to the routine use of choline(11C) is the short physical half life of carbon-11 (20 minutes) that requires a cyclotron in the close vicinity of the PET centre. Several choline analogues labelled with fluorine-18 has been developed to circumvent this logistical limitation, as the $110 \mathrm{~min}$ physical half-life of fluorine 18 is more suited for delivery. Fluoromethylcholine(18F) or FCH (DeGrado et al., 2001) has been the most widely used, as its biodistribution is rather similar to that of choline-(11C), even though its urinary excretion is greater (DeGrado et al., 2002). Acquisition of early PET/CT images of the pelvis (preferably dynamic acquisition from 1 to $8 \mathrm{~min}$ post injection) allows the visualisation of abnormal uptake in the prostate bed or the pelvic lymph node basins before high urine activity enters the ureters and the urinary bladder. The same team demonstrated the superiority of $\mathrm{FCH}$ over FDG to detect prostate cancer tissue, regardless to its dependence to androgens (Price et al., 2002).

The current data supporting a potential clinical usefulness of $\mathrm{FCH}$ in prostate cancer will be

\footnotetext{
${ }^{*}$ Author for correspondence
} 
briefly reviewed, according to precise clinical settings: detecting cancer within the prostate gland and guiding biopsy for its assessment, primary staging of prostate cancer, determination of the biological tumour volume for radiotherapy, detection and restaging of recurrent prostate cancer.

\section{Detecting cancer inside the prostate gland and guiding biopsy for its assessment}

Kwee et al. (2005) demonstrated on biopsy specimens that FCH uptake was significantly greater in pathologic prostate tissue than in healthy tissue. But this increase in FCH uptake was not specific for cancer tissue and was also observed in benign hypertrophy or in prostatitis. In series of 17 patients, 6 patients had strictly unilateral cancer and FCH PET/CT accurately showed which prostate lobe was harbouring cancer. However, Schmid et al. (2005) reported that an exact correspondence between FCH PET/CT anomalies and cancer tissue was observed only in 1 of 9 patients who underwent radical prostatectomy; in the other cases, the focus with high $\mathrm{FCH}$ uptake was larger than the cancer tissue or complementary foci actually corresponded to benign hypertrophy. To enhance specificity, Kwee et al. (2006) then proposed dual time point imaging at $7 \mathrm{~min}$ and $60 \mathrm{~min}$ after re-voiding: in 26 patients, FCH uptake increased with time in malignant prostate lesions and decreased in benign lesions. Recently, the same team reported results of the analysis of 90 prostate sextants in 15 patients who underwent FCH PET prior to radical prostatectomy (Kwee et al., 2008). In 13 patients, the sextant with the highest SUVmax corresponded to the largest tumour in the specimen. Authors conclude that FCH PET can serve to localise the dominant areas of malignancy but may fail to identify sextants with smaller volumes of malignancy. Those results may favour the use of FCH PET in patients with persistent elevated PSA and repeated negative prostate biopsy to guide renewed prostate biopsy. The team in Klagenfurt recently reported on FCH PET/CT performed in 20 such patients (Igerc et al., 2008): in 5 patients, FCH PET/CT allowed the identification of neoplastic lesions. Complementary information was derived from this study: semiquantitative analysis with SUVmax and dual-phase acquisition protocol were not helpful in the discrimination of malignancy.
Primary staging of prostate cancer and determination of the biological tumour volume for radiotherapy

The drawbacks of FCH PET to localise cancer tissue inside the prostate gland have been reported in the previous paragraph: limited sensitivity for small lesions in multifocal cancer and limited specificity due to uptake in benign lesions. Nevertheless, the team in Zurich considered that FCH PET/CT might serve for semi automatic segmentation for radiotherapy of prostate cancer. A preliminary study in 10 patients with prostate cancer and no extracapsular growth aimed to determine the optimal threshold to be used for lesion contouring (Ciernik et al., 2007). Concerning the detection of distant cancer metastases, FCH PET/CT could be helpful, in particular in a subgroup of patient at risk for such a spread : initial Gleason score $>7$ or PSA serum level $>10 \mathrm{ng} / \mathrm{mL}$ or a doubling time of PSA serum levels $<3$ months. In series of 49 such patients, Langsteger et al. (2006) reported a $4 \%$ rate of downstaging (unconfirmed suspicion of bone metastases) and a $16 \%$ rate of upstaging (unexpected bone metastases in 4 cases and multiple lymph node metastases in 2 cases) with an impact on management. However, the detection of microscopic lymph node metastases benefits from sentinel lymph node detection which is more sensitive than conventional lymph node detection even including the obturator basin. In the study of Hacker et al. (2006) who used sentinel node histology as the standard of truth, all lymph node metastases of a size greater than $8 \mathrm{~mm}$ were identified ; but in $10 \mathrm{~N}+$ patients there was only on a per patient basis 1 true-positive vs. 9 false negative results. These results were recently confirmed by the team in Zurich in 43 patients referred for initial staging (Husarik et al., 2008) with a mean PSA serum level of $12 \mathrm{ng} / \mathrm{mL}$ : on a per patient basis, there was 1 true positive case vs. 4 false negative case for the detection of lymph node metastases while all 4 cases of bone metastases were true-positive. In summary, FCH PET seems to be useful in the pre-treatment staging of high risk prostate cancer to warn for unknown distant spread or better characterise lesions suspicious on conventional imaging (Gutman et al., 2006), which may have an impact on management; in contrast, a negative examination does not rule out a minimal invasion of the contiguous organs (seminal vesicles) or of regional lymph nodes. 


\section{Search for recurrence}

This setting seems to be the most promising for FCH PET/CT in prostate cancer. In preliminary series of 9 patients presenting with a biochemical recurrence (isolated rising serum PSA levels, 14 $\mathrm{ng} / \mathrm{mL}$ on average at FCH imaging), FCH PET/CT brought in evidence in 3 cases an isolated local recurrence, in 4 cases no local recurrence but lymph node invasion which was checked by histology and confirmed in 2 cases, in 1 case both localisations, and in the final case bone metastases which were also visible on bone scintigraphy (Schmid et al., 2005). It has subsequently been shown by the team in Linz that recurrent prostate cancer could be detected on FCH PET/CT even when serum PSA levels were less than $5 \mathrm{ng} / \mathrm{mL}$ (Heinisch et al., 2006): a true positive result was obtained in $41 \%$ of the 17 patients. In the already quoted study from Zurich (Husarik et al., 2008), 68 patients were referred for restaging, with a mean PSA serum level of $11 \mathrm{ng} / \mathrm{mL}$, and 57 had pathological FCH accumulation. Overall sensitivity to detect recurrent disease was $86 \%$ and $71 \%$ when serum PSA levels were less than 2 $\mathrm{ng} / \mathrm{mL}$. The team in Aviano studied 100 patients with suspected recurrent disease (Cimitan et al., 2006). Recurrence was detected on FCH PET/CT in 54 patients with mean serum PSA levels of 48 ng/mL: 21 patients with bone metastases, 17 with local recurrence including 7 who also had distant metastases, 7 with isolated abdominopelvic lymph node involvement, and 9 with both nodal and bony metastases. In contrast in 46 patients FCH PET/CT did not show any anomaly and no other imaging modality was able to detect recurrent disease in any of them during a 6 month follow-up; their PSA serum levels were much lower $(2 \mathrm{ng} / \mathrm{mL}$ on average). The detection rate of recurrence with FCH PET/CT depended on PSA serum levels and the initial Gleason score, from $8 \%$ in the group with PSA $<4 \mathrm{ng} / \mathrm{mL}$ and intial Gleason score less than or equal to 7 , up to $100 \%$ with PSA > 4 $\mathrm{ng} / \mathrm{mL}$ and initial Gleason score greater than 7; $89 \%$ of the patients with non-contributive $\mathrm{FCH}$ PET/CT examinations had serum PSA levels below $4 \mathrm{ng} / \mathrm{mL}$. The intensity of the uptake by some bone metastases increased with time which could justify the acquisition of delayed images (60 min) when the early images are negative.

The experience of our team on 106 FCH PET/CT which were performed for suspicion of prostate cancer recurrence, based on a persistent increase in PSA serum levels, has been published in an abstract form (Huchet et al., 2007). Our aim was to find a better criterion than PSA serum levels to select patients whose recurrence is likely to be detected with FCH (56/106 in our series). High PSA absolute velocity permitted to pinpoint patients with PSA levels $<5 \mathrm{ng} / \mathrm{mL}$ in whom $\mathrm{FCH}$ $\mathrm{PET} / \mathrm{CT}$ was subsequently positive, while relative PSA velocity was of no help.

\section{Therapy monitoring and interference}

To the best of our knowledge, there is currently no data available on the early evaluation with $\mathrm{FCH}$ PET of hormonal treatment. Although there is no formal study published on the evaluation of invasive therapy with $\mathrm{FCH}$, the detection of persistent disease is possible and useful when no significant drop in PSA serum levels is observed after local therapy; such a case has been illustrated by our team (Talbot et al., 2007 - fig 5).

The team in Geneva performed FCH PET/CT in 11 patients who had low but significant PSA serum levels, between 0.08 and $0.76 \mathrm{ng} / \mathrm{mL}$, after radical prostatectomy and were scheduled for adjuvant or salvage radiotherapy (Vees et al., 2007). Foci of local recurrence were visible in 5/11 patients with no distant lesion while endorectal MRI was locally positive in 10 . However, the only patient with a negative endorectal MRI was locally positive on the FCH PET/CT, and he responded to salvage radiotherapy with a decreasing PSA level. Authors do not recommend $\mathrm{FCH}$ PET/CT as a standard diagnostic tool for early relapse or suspicion of minimally persistent disease after surgery. The performances of acetate-(11C) determined in a parallel group were not clearly superior.

The potential reduction of the diagnostic performances of FCH PET/CT by anti-hormone treatment has not been addressed in a specific study. In our experience, when serum PSA levels are high enough during anti-hormone treatment, it is not justified to interrupt the treatment to perform FCH PET/CT. In the series of 68 patients referred for biological recurrence reported by Husarik et al. (2008), 13 were receiving anti-hormone therapy and only two of their examinations did not show any pathological $\mathrm{FCH}$ accumulation. In the other 11 treated patients, at least one site of pathological FCH uptake was confirmed to be metastatic disease or local recurrence. Sensitivity at any PSA level was $84 \%$ in patients with anti-hormone therapy, similar to $83 \%$ without anti-hormone therapy. 
In contrast, it is probable that conventional chemotherapy, when indicated in androgen independent cancer, would lead to false negative results if an appropriate delay after the last administration would not be not observed ; neither its duration nor the interpretation criteria of interim FCH PET/CT and its predictive values are currently assessed.

\section{Perspectives of registration of $\mathrm{FCH}$ in $\mathrm{EU}$}

An application for marketing authorisation of $\mathrm{FCH}$ can be foreseen in EU, as PET/CT has a growing importance in oncologic imaging and as there is a need for an accurate radiopharmaceutical in prostate cancer. As already illustrated in this journal by the example of FDOPA-(18F) registration (Chevalme et al., 2007), a demonstration of clinical utility is required (assuming that quality and safety of the compound are absolute). This concept integrates technical performances, diagnostic performances (trade off between sensitivity and specificity) and impact on diagnostic thinking and patient management. Usually this implies the demonstration of superiority over a comparator. In the case of FCH registered radiopharmaceuticals to be used as comparators are limited to bisphosphonates$(99 \mathrm{mTc})$ or sodium fluoride- $(18 \mathrm{~F})$ for the detection of bone metastases (initial staging and restaging). However, no registered radiopharmaceutical is available for the detection of soft tissue foci which is also a potential indication of $\mathrm{FCH}$, except for the detection of sentinel lymph node which will be a powerful concurrent for initial $\mathrm{N}$ staging (as it is for FDG in many other malignancies). Thus MRI could be used as a comparator in supportive studies. Three PET radiopharmaceuticals are currently registered in France: FDG-(18F), FDOPA-(18F) and sodium fluoride-(18F). The demonstration of their clinical utility in the claimed indications has been done on bases of "well established use" for more than 10 years and thanks to a bibliographic analysis. This opportunity will not been open for FCH before 2012: its potential use in prostate cancer has been published in 2001 (DeGrado et al., 2001), but the first comparative study in this indication was published the same team in 2002 (DeGrado et al., 2002). FCH could possibly be the first PET radiopharmaceutical to be registered earlier, on bases of phase III pivotal studies.

\section{CONCLUSION}

The FCH PET/CT could become a major tool in case of biologic recurrence of prostate cancer to detect early and accurately bone and/or visceral involvement. For the same reason, it could be clinically useful for the initial staging of advanced prostate cancer, mostly in search for distant metastases, since results for initial $\mathrm{N}$ staging were "discouraging" (Husarik et al., 2008). Its impact on patient management in these settings has still to be assessed and quantified. Its role (if any) in guiding prostate biopsy to assess cancer, helping to determine radiotherapy target volumes and early therapy evaluation remains to be evaluated in comparison with other imaging modalities, in particular endorectal MRI with diffusion.

\section{RESUMO}

Esta breve revisão é dedicada ao estado atual da avaliação de um novo radiofármaco PET, a fluormetilcolina-(18F) ou FCH, que é captada pelo tecido do câncer de próstata, ao contrário da fluordesoxiglicose-(18F) ou FDG. Parece que a FCH poderia se tornar "a FDG do câncer de próstata", com o mesmo tipo de funções (detecção de metástases distantes e de recorrências ocultas, antes de tratamentos invasivos), e os mesmos inconvenientes (falso resultado negativo no caso de pequenas lesões, em especial das metástase de nodos linfáticos, e de falsos resultados positivos em caso de infecção/inflamação, em particular prostatite). Evidência atual é resumida e discutida para cada uma das definições potenciais da imagem FCH PET/CT em câncer de próstata. As perspectivas para a concessão de uma autorização de comercialização para uma preparação de $\mathrm{FCH}$ são analisadas brevemente.

Palavras-chave: fluorometilcolina-(18F), PET/CT, cancer de próstata, avaliação de radiofármacos

\section{REFERENCES}

Chevalme, Y. M. ; Montravers, F. ; Vuillez, J. P. ; Zanca, M.; Fallais, C.; Oustrin, J.; Talbot, J. N. (2007), FDOPA-(18F): a PET radiopharmaceutical recently registered for diagnostic use in countries of the European Union. Braz Arch Biol Technol., 50, 7790. 
Ciernik, I. F.; Brown, D. W.; Schmid, D.; Hany, T.; Egli, P.; Davis, J. B. (2007), 3D-segmentation of the 18F-choline PET signal for target volume definition in radiation therapy of the prostate. Technol Cancer Res Treat., 6, 23-30.

Cimitan, M.; Bortolus, R. ; Morassut. S.; Canzonieri, V.; Garbeglio, A.; Baresic, T.; Borsatti, E.; Drigo, A.; Trovò, M. G. (2006), [18F]fluorocholiine PET/CT imaging for the detection of recurrent prostate cancer at PSA relapse: experience in 100 consecutive patients. Eur J Nucl Med Mol Imaging., 33, 13871398.

DeGrado, T. R.; Coleman, R. E.; Wang, S.; Baldwin, S. W.; Orr, M. D.; Robertson, C. N.; Polascik, T. J.; Price, D. T. (2001), Synthesis and evaluation of 18Flabeled choline as an oncologic tracer for positron emission tomography: initial findings in prostate cancer. Cancer Res., 61, 110-117.

DeGrado, T. R.; Reiman, R. E.; Price, D. T.; Wang, S.; Coleman, R. E. (2002), Pharmacokinetics and radiation dosimetry of $18 \mathrm{~F}$-fluorocholine. $\mathrm{J} \mathrm{Nucl}$ Med., 43, 92-96.

Gutman, F; Aflalo-Hazan, V.; Kerrou, K.; Montravers, F.; Grahek, D.; Talbot, J. N. (2006), 18F-choline PET/CT for initial staging of advanced prostate cancer. AJR Am J Roentgenol., 187, W618-621.

Hacker, A.; Jeschke, S.; Leeb, K.; Prammer, K.; Ziegerhofer, J.; Sega, W.; Langsteger, W.; Janetschek, G. (2006), Detection of pelvic lymph node metastases in patients with clinically localized prostate cancer : comparison of [18F] fluorocholine positron emission tomography - computerized tomography and laparoscopic radioisotope guided sentinel lymph node dissection. J Urol., 176, 20142018.

Heinisch, M.; Dirisamer, A.; Loidl, W.; Stoiber, F.; Gruy, B.; Haim, S.; Langsteger, W. (2006), Positron emission tomography/computed tomography with F18-fluorocholine for restaging of prostate cancer patients: meaningful at PSA $<5 \mathrm{ng} / \mathrm{ml}$ ? Mol Imaging Biol., 8, 43-48.

Huchet, V.; Gutman, F.; Kerrou, K. et al. (2007), Evaluation of PSA velocity as a selection criterion for $\mathrm{FCH}$ PET/CT in patients with biological recurrence of prostate cancer. Eur J Nucl Med Mol Imaging., 34, S123.

Husarik, D. B.; Miralbell, R.; Dubs, M.; John, H.; Giger, O. T.; Gelet, A.; Cservenyàk, T.; Hany, T. F.. (2008), Evaluation of (18F)-choline PET/CT for staging and restaging of prostate cancer. Eur $\mathrm{J} \mathrm{Nucl}$ Med Mol Imaging., 35, 253-263.
Igerc, I.; Kohlfürst, S.; Gallowitsch, H. J.; Matschnig, S.; Kresnik, E.; Gomez-Segovia, I.; Lind, P. (2008), The value of $(18 \mathrm{~F})$-choline PET/CT in patients with elevated PSA-level and negative prostate needle biopsy for localisation of prostate cancer. Eur J Nucl Med Mol Imaging, Epub.

Kwee, S. A. ; Thibault, G. P. ; Stack, R. S.; Coel, M. N.; Furusato, B.; Sesterhenn, I. A. (2008), Use of step-section histopathology to evaluate (18F)fluorocholine PET sextant localization of prostate cancer. Mol Imaging, 7, 12-20.

Kwee, S. A.; Coel, M. N.; Lim, J.; Ko, J. P. (2005), Prostate cancer localization with 18fluorine fluorocholine positron emission tomography. J Urol., 173, 252-255.

Kwee, S. A.; Wei, H.; Sesterhenn, I.; Yun, D.; Coel, M. N. (2006), Localization of primary prostate cancer with dual-phase 18F-Fluorocholine PET. J Nucl Med., 47, 262-269.

Langsteger, W.; Heinisch, M.; Fogelman, I. (2006), The role of fluorodeoxyglucose, 18Fdihydroxyphenylalanine, $18 \mathrm{~F}$-choline, and 18Ffluoride in bone imaging with emphasis on prostate and breast. Semin Nucl Med., 36, 73-92.

Price, D. T.; Coleman, R. E.; Liao, R. P.; Robertson, C. N.; Polascik, T. J.; DeGrado, T. R. (2002), Comparison of $[18 \mathrm{~F}]$ fluorocholine and [18F]fluorodeoxyglucose for positron tomography of androgen dependent and androgen independent prostate cancer. J Urol., 168, 273-280.

Schmid, D. T.; John, H.; Zweifel, R.; Cservenyak, T.; Westera, G.; Goerres, G. W.; von Schulthess, G. K.; Hany, T. F. (2005), Fluorocholine PET/CT in patients with prostate cancer: initial experience. Radiology., 235, 623-628.

Talbot, J. N.; Gutman, F.; Huchet, V.; Kerrou, K.; Balogova, S.; Kerrouche, N.; Montravers, F.; Grahek, D.; Cussenot, O.; Gattegno, B.; Thibault, P. (2007), Utilité clinique de la tomographie par émission de positons dans le cancer de la prostate. Presse Med., 36, 1794-1806.

Vees, H.; Buchegger, F.; Albrecht, S.; Khan, H.; Husarik, D.; Zaidi, H.; Soloviev, D.; Hany, T. F.; Miralbell, R. (2007), 18F-choline and/or 11C-acetate positron emission tomography: detection of residual or progressive subclinical disease at very low prostate-specific antigen values $(<1 \mathrm{ng} / \mathrm{mL})$ after radical prostatectomy. BJU Int., 99, 1415-1420.

Received: August 20, 2008; Accepted: September 03, 2008. 